San Jose State University

From the SelectedWorks of David W. Parent

October, 2018

\title{
Development of a placement exam to increase student success in a junior level circuits and systems class
}

David W Parent, San Jose State University 


\title{
Development of a placement exam to increase student success in a junior level circuits and systems class
}

\author{
David W. Parent \\ Electrical Engineering \\ San Jóse State University \\ San Jóse, CA 95192 \\ David.Parent@sjsu.edu
}

\begin{abstract}
In this work, which is intended to be a Full Paper in the Innovative Practice Category, the implementation of an improved placement exam that increased the pass rate in a junior level systems course in the author's electrical engineering department by $15 \%$ is presented. For almost 30 years the author's EE department has used a face to face exam to place students in a junior level circuits and systems course or into a review workshop. The details of the exam and suggestions about future use in conjunction MyOpenMath analytics to increase student success are also given.
\end{abstract}

Index Terms - Circuits and systems, student success, placement exam, MyOpenMath, entry behaviors

\section{INTRODUCTION}

For almost 30 years the author's electrical engineering department has used a face to face multiple choice exam to place students in a junior level circuits and systems course. The exam consisted questions from the following topic areas: basic physics, DC circuits, AC circuits, transients, and differential equations. The main reason given by Professor James Freeman (private interview spring 2018) for using this placement exam was the fact that the junior level systems class had the largest DFW rate (percentage of students who earn a $\mathrm{D} \mathrm{F}$ or $\mathrm{W}$ ) in the department and the reason given for this high DFW rate was that the pre-requisite introduction to circuit analysis course could not be used to reliably ensure transfer students were prepared. The importance of transfer student skill verification was that our program could have up to $50 \%$ of its students transfer from a local community college and the standard of the pre-requisite circuit analysis course (C-ID 260) at the local community colleges could not be verified or controlled by the author's program. It was claimed that the DFW rate decreased after the exam was implemented. In the past community colleges were notified if their students did poorly on certain classes of questions (such as transients). In addition, some local community colleges adopted the placement exam (created from a public problem bank) for their final exam in the introduction to circuit analysis course.

While there is no reason to doubt the early success of the exam, there were several reasons to revisit the structure and purpose of this exam. The first reason to reexamine the exam was that it seemed that the DFW rate for the systems class had increased over the years regardless of instructor. Furthermore, during advising students would complain to the author that the exam was just another barrier to entry to their studies. Students would fall into two groups where one group felt the exam was too easy to pass because the exam did not change much and the distractors (wrong, but reasonable answers) were predictable and the other group who felt they did not pass the exam because they has misjudged how many questions to answer. (Students would lose only one point for not answering a question, but would lose four points for answering a question incorrectly). The final reason for developing a new exam was that the questions the exam could be passed without correctly answering the questions that directly related to the follow on circuits and systems course. This happened because the questions on the original exam were too broad and the passing grade was set only to $60 \%$. Question topics that did not seem to relate to the material needed in the circuits and systems class were: energy stored in an inductor or capacitor non-linear differential equations, Thevenin, and Norton equivalent circuits.

It was decided by the faculty to fix the exam rather than stop using it, even though it appears only two other schools in the US use an exam to verify pre-requisite skills for upper division courses. One example of a similar exam to the author's is the EE department of UC San Diego [1]. UCSD's EE department makes all community college transfer students take waiver exams to verify their circuits and programming knowledge. If students do not pass the exam they have retake these courses at UC San Diego. The EE department at USC [2] has a series of pre-requisite waiver exams that newly admitted graduate students take so they can bypass undergraduate level pre-requisites that exist for some graduate level courses.

While it appears that most schools do not use a placement exam for junior level engineering classes, faculty and universities do rely on placement exams for freshman math courses [3-6] and of course the SAT, ACT and GRE (along with GPA) are used to accept for student admissions [7-9].

\section{EXAMINATION DETAILS}

\section{A. Previous Exam Structure}

The previous exam consisted of 25 multiple choice items drawn from a bank of questions that tested all EE concepts that a student would learn in their physics, math (including differential equations) and introduction to electrical engineering courses. The passing grade for the old exam was 
$60 \%$ with four points added for every correct answer, four points subtracted for every wrong answer, and 1 point subtracted for not answering. The reason for this grading scheme was that it was supposed to prevent guessing.

The exam was given once at the end of the semester for those who were finishing their introduction to circuit analysis course at the author's institution and once at the beginning of the next semester for those who did not pass the first time and transfer students who completed the introduction to circuit analysis class at a community college. The exams were graded and the results posted as soon as possible. When a student passed the exam they were put into a database group that would allow them to enroll in the circuits and systems course. (Pre-requisites were not consistently checked.) Students who did not pass the exam had to enroll in a workshop that reviewed all the topics of the test and had to delay enrolling in the circuits and systems course until they could past before the next semester started.

\section{B. Improved Exam Structure}

The first improvement was to limit the questions to topic areas that support the learning objectives of the circuits and systems course. These topics areas are first and second order transient analysis, complex number analysis (phasor analysis), OPAMP applications, nodal and mesh analysis, root mean square determination, as well as finding the Laplace transform of common functions.

The second improvement was to set the pass rate to $80 \%$, which insures that a student cannot pass unless they correctly answer at least one question in each section.

The third improvement was to use MyOpenMath to program sample tests so the students could practice with a non-static question bank. The online sample exam selects random questions from a fixed bank of questions, randomizes the order of the items and inserts random distractors that make sure the correct answer is not easily predicted by the relationship to the distractors. In addition, online help videos were embedded in the online version of the test. A brief video about "distractors" in multiple choice questions was created for the students as well. The sample exam generator can be accessed by currently enrolled students through the university's canvas learning management system (LMS). Transfer students can access the online sample exams via the MyOpenMath LMS.

The final improvement was to make a policy where students are required to earn $80 \%$ or better on the online version of the exam before they take the face to face exam, which ensures that they are better prepared. In practice, if a student shows up for the exam without earning $80 \%$ on the online practice exam they are allowed to take it to avoid confrontations while other students are taking the exam. The number of these

\footnotetext{
1 A negative resistance could arise from an abstraction of a negative differential resistance circuit, or if the RLC circuit is modeling an equivalent but unstable physical system.
}

students who do not prepare is rare (one per exam) and they never pass.

Pre-requisites are checked for each student after a student submits their transcripts online. Even if a student passes the exam, they not allowed to take the follow on circuits and systems course without earning a $\mathrm{C}$ or better in the prerequisite circuits and differential equations courses.

\section{Typical Examination Questions}

The exam consists of randomly selected questions from six question banks: Transients, Phasors, Passive energy storage elements and complex numbers, OPAMP problems, Nodal/Mesh problems, and Mathematical problems.

\section{1) Transient Problems (six questions)}

Figure 1 shows a typical first order problem. Students are given $\mathrm{R}_{1}, \mathrm{R}_{2}$, and $\mathrm{I}_{0}$ and select the best transient response. Other variations include $\mathrm{RC}$ circuits and various configuration of resistors that alter the time constant.

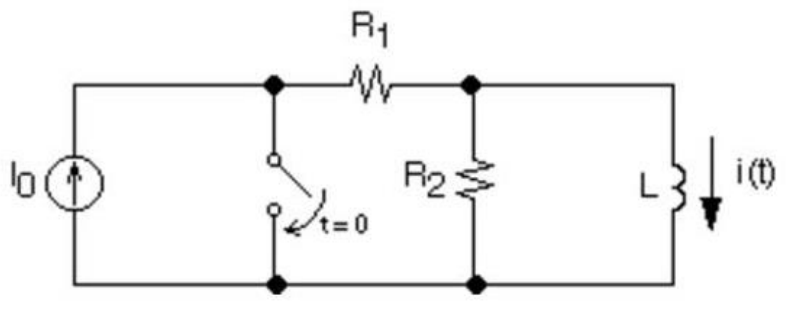

Fig. 1: Typical first order RLC transient problem.

The students select from the following typical answers:

A. $1.25 \cdot e^{-t \cdot 5}$

B. $1.25 \cdot e^{-t \cdot 8}$

C. $1.25 \cdot e^{-t \cdot 0.1}$

D. $1.25 \cdot e^{-t \cdot 10}$

E. $1.25 \cdot e^{-t \cdot .5}$

Figure 2 shows a sample RLC problem. The students are given values for $\mathrm{R}, \mathrm{L}$, and $\mathrm{C}$ and then choose the transient response that represents, over, under, or critical damped response. There are two possible unstable responses, one when $\mathrm{R}$ is negative ${ }^{1}$ and one when the resistance is $\infty$ (missing). The other option for this type of questions is the series RLC configuration.

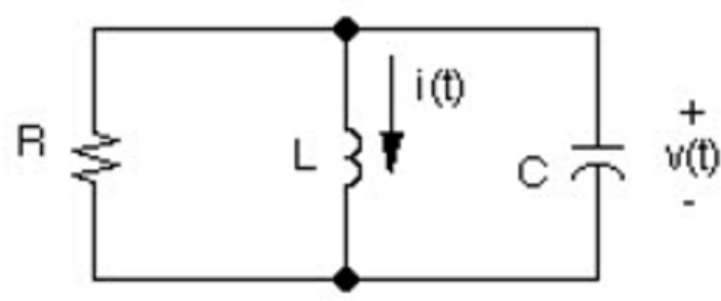

Fig. 2: Typical second order RLC transient problem. 
The students select from the following typical answers:
A. $\quad A \cdot \cos (B \cdot t+\phi)$
B. $A_{1} \cdot e^{-B_{1} \cdot t}+A_{2} \cdot e^{-B_{2} \cdot t}$
C. $\left(A_{1}+A_{2} \cdot t\right) \cdot e^{-B \cdot t}$
D. $A \cdot e^{-B_{2} \cdot t} \cdot \cos \left(B_{1} \cdot t+\phi\right)$
E. $A \cdot e^{B_{1} \cdot t} \cdot \cos \left(B_{2} \cdot t+\phi\right)$

\section{2) Phasor Problems (six questions)}

Figure 4 shows a phasor problem where the students are given the impedance of each device and with the input current magnitude and phase determine the output voltage in phasor form. Other questions would have different configurations of $\mathrm{R}, \mathrm{L}$ and $\mathrm{C}$.

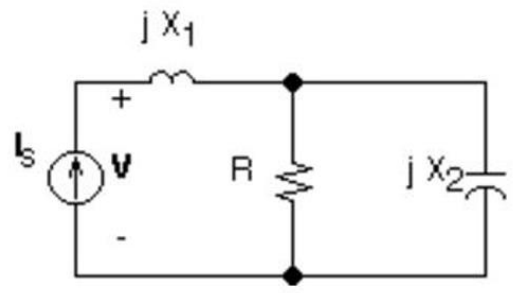

Fig. 4: Typical phasor problem.

The students select from the following typical answers:
A. $2+2 j$
B. $4+4 j$
C. $3+3 j$
D. $9+9 j$
E. $10+10 j$

Figure 5 shows another sample phasor problem. In this type of problem students are given the input current and the values for $\mathrm{R}, \mathrm{L}$, and $\mathrm{C}$. They have to calculate the impedance for the inductor and capacitor be extracting $\omega$ from the time domain description of the sinusoidal input. And use that in conjunction with the magnitude and phase of the input current to find the output voltage in phasor form. Other questions have different circuit configurations.

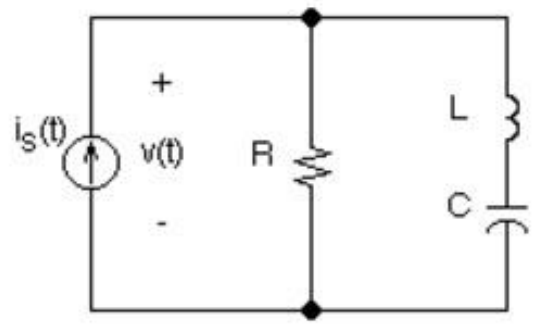

Fig. 5: Typical phasor problem with a higher level of difficulty.

The students select from the following typical answers:
A. $12 \cdot \cos (8 \cdot t+60)$
B. $12 \cdot \cos (8 \cdot t+90)$
C. $12 \cdot \cos (8 \cdot t-60)$
D. $12 \cdot \cos (8 \cdot t+45)$
E. $12 \cdot \cos (8 \cdot t-45)$

\section{3) Passive energy storage and complex number problems (two questions)}

A typical complex number problem would be:

\section{Simplify $i^{5}$ and convert into polar form.}

The students select from the following typical answers:
A. 0
B. $1<-180^{\circ}$
C. $1 \angle 0^{\circ}$
D. $1 \angle 90^{\circ}$
E. $1 \angle-90^{\circ}$

Other questions form this group ask intuitive questions about capacitors and inductors such as:

\section{The impedance of an ideal capacitor is:}

The students select from the following answers:
A. zero at DC
B. constant with frequency
C. imaginary
D. a sinusoidal function of frequency
E. indeterminate

Other questions in the section deal with complex number manipulation in exponential form.

\section{4) OPAMP Problems (five questions)}

Figure 6 shows an OPAMP (assumed to be ideal) problem in which the students are given values for $I_{1}, V_{1}, R_{1}$, and $R_{L}$ and asked to find the output voltage. Other configurations have different superposition configurations, current to voltage converters, or ask for the current though $\mathrm{R}_{\mathrm{L}}$. Basic inverting and noninverting configurations questions are also in this question bank.

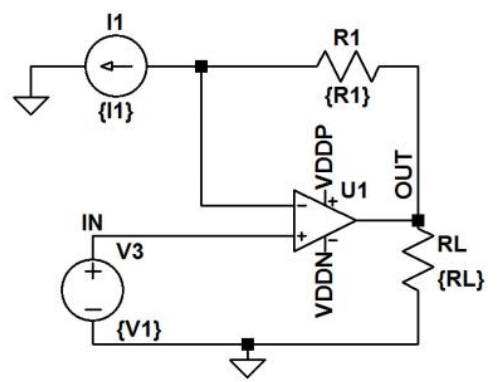

Fig. 6: Typical OPAMP superposition question. 
The students select from the following typical answers:
A. -3
B. 0.5
C. 9
D. 2.5
E. $-9 \mathrm{~V}$

Figure 7 shows a sample OPAMP (assumed to be ideal) question where the students are input an input voltage and resistance values and calculate the output voltage. Other questions would have both inverting and noninverting configurations in different order.

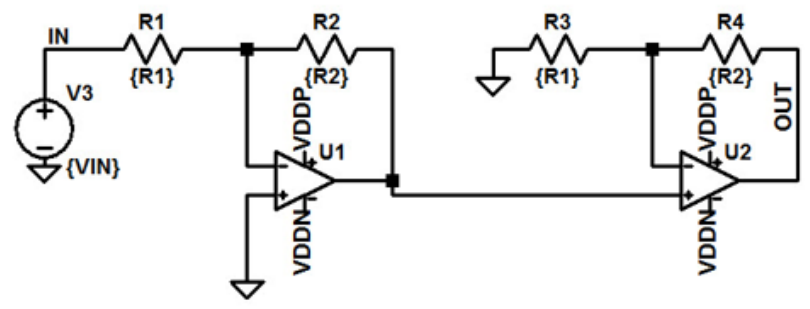

Fig. 7: Typical cascaded gain OPAMP question.

The students select from the following answers:
A. -1.2
B. 1.2
C. 24
D. -1.8
E. 1.8

\section{5) Nodal/Mesh (three questions)}

Figure 8 shows a sample nodal equation problem where the students are given realistic values of $\mathrm{I}_{\mathrm{R} 3}, \mathrm{I}_{\mathrm{R} 4}, \mathrm{I}_{+}$(into positive input of the OPAMP) and are asked to find the current flowing though the diode. Other problems would be identifying how many nodal equations a particular circuit needs to solve for the voltages and currents.

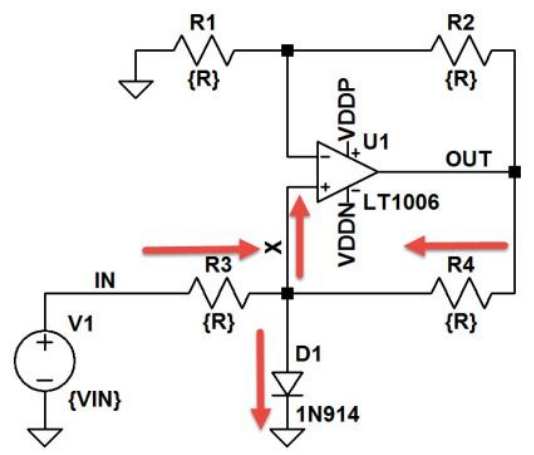

Fig. 8: Typical nodal analysis problem.

The students select from the following typical answers:
A. $\quad 513.99$
B. -624.01
C. 493.99

D. 624.01

E. $\quad-503.99$

Figure 9 shows a sample mesh problem where the students are given all resistance values, input voltages, and $\beta$, and are asked to find $V_{R E}$ or $V_{R C}$. Other mesh questions problems would be identifying how many mesh equations a particular circuit needs to solve for the voltages and currents.

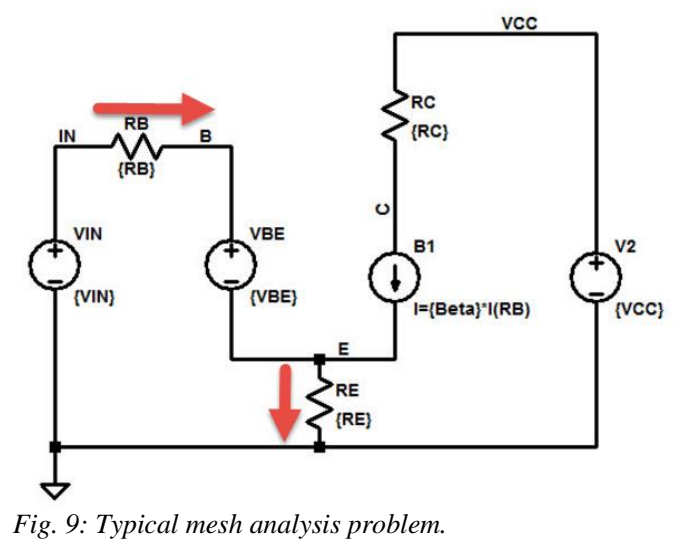

The students select from the following typical answers:
A. $\quad 0.3197$
B. 0.0032
C. 0.6329
D. 0.0043
E. 0.3229

\section{6) Mathematical Problems (three questions)}

The mathematical problem set consists of two questions on finding the Laplace transform of two various signals for example: $f(t)=4 \cdot t \cdot e^{-3 \cdot t}$

The students select from the following typical answers:
A. $\frac{4}{s}-\frac{4}{s-3}$
B. $\frac{4}{s+3}$
C. $\frac{3}{s^{2}}$
D. $\frac{4}{(s+3)^{2}}$
E. $\frac{4}{s+3}+\frac{4}{s+3}$

Other signals would be step, ramp, double exponential, asymptotic double exponential, and asymptotic critically damped. 
The final question from this group is where the students calculate the RMS value of pulse width modulated signals and two types of triangle waves.

The students select from the following typical answers:
A. 2.47
B. 1
C. 0.004
D. 1.155
E. $\quad 5.33$

\section{RESULTS AND DISCUSSION}

Once the new exam was used, (still given face to face) the pass rate (percentage of students who earned a $\mathrm{C}$ or better.) in the circuits and systems class improved from $70 \%$ to $85 \%$. This improvement has held steady even when the instructor was changed. Not every student passes the first time they take the placement exam and if they cannot pass before the start of the semester they are encouraged to take a workshop to improve their skills. So far all students have passed the exam eventually.

The typical face to face pass rate of the exam ranges from 50 to $60 \%$ as shown in table 1 . The 23 January exam had a higher pass rate possibly because online webinar were offered over winter break. Another reason for the high pass rate was that a sample exam generator that allowed the students to see more questions from the bank. The second exam was given because enrollment was too low and more students were needed to pass to be able to offer two sections of the circuits and systems class. This might not have been a good idea in that is seems that these students who passed late are not doing well in the course. Currently three students from this group of "late passers" are passing the course and six are failing.

The pass rate for the exam DEC 2017 workshop (WSHP) had an above average pass rate as well. This is encouraging because this group took the exam as part of a voluntary one unit workshop that reviewed all the content of the exams and had mini-exams where immediate feedback was given in class. Because these mini-exams were hand graded, student misconceptions could be addressed in real time. Of course since the workshop was voluntary, it could be the student and not the treatment that could behind the improved pass rate.

Another interesting development is that the students who passed early for the spring 2018 semester (everything prior to the 23 JAN test) all chose one section of a popular professor and that section seems to be having above average results. This could indicate that it is not the improved exam by itself that is causing the improved pass rates, but the reality that students who do not procrastinate tend to do better.

Table 1: Pass rate information for face to face exams.

\begin{tabular}{|c|c|c|c|c|c|c|c|}
\hline & $\begin{array}{l}\text { DEC } \\
2016\end{array}$ & $\begin{array}{l}\text { AUG } \\
2017\end{array}$ & $\begin{array}{c}\text { MAY } \\
2017\end{array}$ & $\begin{array}{c}\text { DEC } \\
2017 \\
\text { WRSP }\end{array}$ & $\begin{array}{l}\text { DEC } \\
2017\end{array}$ & $\begin{array}{c}16 \\
\text { JAN } \\
2018\end{array}$ & $\begin{array}{c}23 \\
\text { JAN } \\
2018\end{array}$ \\
\hline $\begin{array}{c}\# \\
\text { students }\end{array}$ & 46 & 50 & 17 & 24 & 46 & 35 & 16 \\
\hline \# passed & 26 & 30 & 10 & 18 & 26 & 17 & 12 \\
\hline $\begin{array}{l}\text { Pass } \\
\text { rate }\end{array}$ & 57 & 60 & 59 & 75 & 57 & 49 & 75 \\
\hline
\end{tabular}

The learning management system (LMS) used for the questions has a rich set of analytical tools to examine question on the online exam. As shown in Figure 10, the average score on a question, average attempts and time per attempt for each question is shown. Interestingly, the question with the lowest score was calculating the RMS voltage of a square wave with a non-50\% duty cycle. Other low scoring question were RLC transient problems that had a negative resistance, which would result in an unstable system. Maybe these negative resistance problems should be dropped as systems with negative differential resistance are not covered until later in the author's program.

\begin{tabular}{|c|c|c|c|c|c|c|}
\hline$\#$ & Question & Grade & $\begin{array}{l}\text { Average } \\
\text { Score } \\
\text { Attempted }\end{array}$ & $\begin{array}{l}\text { Average } \\
\text { Attempts } \\
\text { (Regens) }\end{array}$ & $\begin{array}{c}\% \\
\text { Incomplete }\end{array}$ & $\begin{array}{l}\text { Time per student } \\
\text { (per attempt) }\end{array}$ \\
\hline $25 \cdot 1$ & EE101 MATH 1 & Grade & $25 \%$ & $6.88(0)$ & $73.8 \%$ & $\begin{array}{l}\begin{array}{l}17.15 \min (2.86 \\
\min )\end{array}\end{array}$ \\
\hline $1-11$ & Transient 45 & Grade & $30 \%$ & $5.1(0)$ & $70.1 \%$ & $\begin{array}{l}30.45 \min (4.61 \\
\min )\end{array}$ \\
\hline $13 \cdot 1$ & DC 41 & Grade & $39 \%$ & $4.46(0)$ & $76.8 \%$ & $\begin{array}{l}7.99 \min (1.21 \\
\min )\end{array}$ \\
\hline 1-17 & Transient 50 & Grade & $40 \%$ & $8.2(0)$ & $68.8 \%$ & $\begin{array}{l}98.51 \min (10.71 \\
\min )\end{array}$ \\
\hline
\end{tabular}

Fig. 10: Analysis tools from MyOpenMath

Another report from MyOpenMath is how many times a student attempted the assignment. There seems to be a wide variance in the number of online attempts with some students looking at it once and other taking it 115 times. While correlating these analytics with student performance in the follow on course should be part of a future study, it seems that the raw data suggest that student who keep retrying problems or taking the exam too many times and not really learning/reviewing the underlying material.

\section{CONCLUSIONS}

While being able to answer updated the exam questions correctly should lead to increased student success, is using the exam as a placement exam worth the cost? Only two other universities use an exam like this $[1,2]$ and maybe it would better to increase student success by adopting other strategies, such as increasing student attendance [10-13], providing supplemental instruction [14, 15], improving teaching/tutoring with online assignments [16, 17], or increasing student engagement [17-20]

The exam could be part of a directed self-placement system in which students have to demonstrate a willingness to do the work to stay enrolled in the systems class [21]. If the homework assignments during the first three weeks of class were automatically graded, the online grades and the MyOpenMath analytics could be used to better advise students. For instance, students could get an accurate prediction of the final grade and then they could decide to stay 
enrolled in the systems class or sign up for a non-degree applicable systems workshop.

Regardless of the ultimate use of the exam (forced placement, or directed self-placement) an analysis of how the exam questions correlate questions to performance in course should be done so that an instructor can better tailor a lecture to the needs of the students.

\section{REFERENCES}

[1] Electrical and Computer Department of UC San Diego (2018) ECE 15/35 Waiver Exams [online]. Available: http://www.ece.ucsd.edu/undergraduate/ece-15-35-waiverexams

[2] Electrical Engineering Department (2018) Placment Exams [online] Available: https://minghsiehee.usc.edu/placementexams/

[3] C.L. Ballard and M.F. Johnson, "Basic math skills and performance in an introductory economics class," The Journal of Economic Education, vol. 35, no. 1, pp. 3-23 2004.

[4] F. Ngo and W.W. Kwon, "Using multiple measures to make math placement decisions: Implications for access and success in community colleges," Research in Higher Education, vol. 56, no. 5, pp. 442-470 2015.

[5] B. Pejcinovic, D. Duncan, P.K. Wong, M. Faust and G. Recktenwald, "Assessment of student preparedness for freshman engineering courses through assessment of math background," in Frontiers in Education Conference (FIE), 2014 IEEE, 2014, pp. $1-5$.

[6] J. Scott-Clayton, "Do high-stakes placement exams predict college success? CCRC working paper no. 41." Community College Research Center, Columbia University 2012.

[7] S.D. Brown, S. Tramayne, D. Hoxha, K. Telander, X. Fan and R.W. Lent, "Social cognitive predictors of college students' academic performance and persistence: A meta-analytic path analysis," J.Vocat.Behav., vol. 72, no. 3, pp. 298-308 2008.

[8] E. Loken, F. Radlinski, V.H. Crespi, J. Millet and L. Cushing, "Online study behavior of 100,000 students preparing for the SAT, ACT, and GRE," Journal of Educational Computing Research, vol. 30, no. 3, pp. 255-262 2004.

[9] M.D. Reisig and C. DeJong, "Using GRE scores and prior GPA to predict academic performance among criminal justice graduate students," Journal of Criminal Justice Education, vol. 16, no. 1, pp. 37-59 2005.

[10] S. Devadoss and J. Foltz, "Evaluation of factors influencing student class attendance and performance," Am.J.Agric.Econ. vol. 78, no. 3, pp. 499-507 1996.

[11] G.C. Durden and L.V. Ellis, "The effects of attendance on student learning in principles of economics," Am.Econ.Rev., vol. 85, no. 2, pp. 343-346 1995.

[12] D.J. Lamdin, "Evidence of student attendance as an independent variable in education production functions," The Journal of educational research, vol. 89, no. 3, pp. 155-162 1996.

[13] D. Romer, "Do students go to class? should they?" Journal of Economic Perspectives, vol. 7, no. 3, pp. 167-174 1993.

[14] V. Fayowski and P. MacMillan, "An evaluation of the supplemental instruction programme in a first year calculus course," International Journal of Mathematical Education in Science and Technology, vol. 39, no. 7, pp. 843-855 2008.

[15] M. Ramirez, "Supplemental instruction: The long-term impact," Journal of Developmental Education, vol. 21, no. 1, pp. 21997.

[16] J. Reisslein, M. Reisslein and P. Seeling, "WIP: Effectiveness of worked examples and fading in introductory electrical circuit analysis for learners of different ability levels," in Frontiers in Education, 2005. FIE'05. Proceedings 35th Annual Conference, 2005, pp. S2H-S2H.

[17] B. Skromme, V. Seetharam, X. Gao, B. Korrapati, B. McNamara, Y. Huang and D. Robinson, "Impact of step-based tutoring on student learning in linear circuit courses," in Frontiers in Education Conference (FIE), 2016 IEEE, 2016, pp. 1-9.

[18] J. Swenson and K. Wendell, "A case study of students' engagement in a control systems homework problem," in Frontiers in Education Conference (FIE), 2016 IEEE, 2016, pp. 1-4.

[19] N. Fang and J. Lu, "Work in progress-a decision tree approach to predicting student performance in a high-enrollment, highimpact, and core engineering course," in Frontiers in Education Conference, 2009. FIE'09. 39th IEEE, 2009, pp. 1-3.

[20] D.H. Schunk and B.J. Zimmerman, "Work habits and selfregulated learning: Helping students to find a "will" from a "way"," in Motivation and self-regulated learning, Routledge, 2012, pp. 209-234.

[21] D.W. Parent, "Novel gateway stay/add policy used to increase student success rates in an introductory circuits class," in Frontiers in Education Conference (FIE), 2017, pp. 1-8. 